\title{
Developing Creative Teaching Module: Business Simulation in Teaching Strategic Management
}

\author{
Nor Liza Abdullah ${ }^{1}$, Mohd Hizam Hanafiah ${ }^{1}$ \& Noor Azuan Hashim ${ }^{1}$ \\ ${ }^{1}$ Faculty of Economics and Management, Universiti Kebangsaan Malaysia, Selangor, Malaysia \\ Correspondence: Nor Liza Abdullah, School of Management, Faculty of Economics and Management, Universiti \\ Kebangsaan Malaysia, 43600 UKM Bangi, Selangor, Malaysia. Tel: 60-389-215-743. E-mail: iza@ukm.my
}

\author{
Received: February 7, $2013 \quad$ Accepted: April 7, $2013 \quad$ Online Published: May 24, 2013 \\ doi:10.5539/ies.v6n6p95 URL: http://dx.doi.org/10.5539/ies.v6n6p95
}

\begin{abstract}
Globalization and liberalization in the business environment have changed the requirements of types and qualities of human capital needed by the corporate sector. In relation to this, business graduates not only need to have theoretical understanding, but they also need to have creative thinking, communication skills and decision making skills based on multidisciplinary knowledge. Simulation game in business education is suggested to fill the gap by exposing students to real business situations. This study evaluates the effectiveness of business simulation in teaching Strategic Management in Faculty of Economics and Management, Universiti Kebangsaan Malaysia (UKM). A total of 48 students participated in the business simulation game and answered a survey at the end of the Strategic Management course. The objective of this paper is to present the findings in terms of contextual and processual context of using business simulation as an approach in teaching strategic management. The important findings of this research are the ability of simulation in transferring theory to practice, applying multidisciplinary knowledge, managing team dynamics, making decisions in uncertainties and managing in realistic situation. This study highlights the potential of business simulations in developing competent business graduates that fulfill the requirements of the industry.
\end{abstract}

Keywords: strategic management, simulation game, teaching, business education, module

\section{Introduction}

Business education nowadays is being criticized for being theoritical-driven and lack of critical thinking, creativity and innovation (Behrman \& Levin, 1984; Hughes, O’Regan \& Wornham, 2008; Snyder \& Snyder, 2008) and this becomes a major challenge to universities. Furthermore, the process of globalization and liberalization of the business world has changed the types and qualities of human capital required by the corporate sector. Therefore, business graduates are not only expected to have theoretical understanding of business, but also communication skills, thinking skills (Chonko \& Caballero, 1991) and the ability to apply multidisciplinary knowledge.

In today's environment, information technology plays a fundamental role in designing new ways of teaching (Aranda, 2007). Traditional approaches such as face to face lecture and exam based evaluation, are limited in two ways; firstly, students tend to perceive that general decision frameworks can be applied in any industry and situation. Secondly, it gives the impression to the students that strategic decision-making is a static process that mainly involves active role of the top managers (MacKay \& McKiernan, 2004). These limitations of traditional approaches in teaching are now being moderated by new approaches such as case studies and computer simulation that incorporate real life elements to expose students to actual situations (Adobor \& Daneshfar, 2006; Aranda, 2007). Real life case studies have been used in teaching business since its multidimensional nature requires a comprehensive analysis by the students. Case studies help in bridging the gap between theory and practice. By using case study as a tool of education, it fulfills the expectation of the corporate sectors to employ graduates with critical thinking skills especially in dealing with complexities and uncertainties in the business world.

Although business case studies provide an avenue to expose students to real life situations, the range of decisional possibilities is still limited due to the static nature of the information given in the case (Mitchell, 2004). Martin and McEvoy (2003) suggested that simulation application that emulates reality with excellent degree of accuracy can be applied to resolve the shortcomings of case study approach. In fact, this approach is 
gaining popularity in education since it offers the possibility of observing the behavioral aspects of the students under pressured conditions. In other words, personal skills and personal attitudes can be jointly observed and evaluated in the process of collective decision-making (Curry \& Moutinho, 1992).

The use of business simulation in the teaching of strategic management will fill the gap between what is required in the market and what is supplied by the education system (Mitchell, 2004). Since strategic management is a capstone course that requires integration of knowledge from other disciplines, the development of critical and analytical thinking will be the main focus of this course. Therefore, business simulation is proposed to effectively enhance student's thinking and skills and it is also suggested to increase student's resilience and maturity especially in handling complex and ambiguous situations that exist in the real business world. This will be a distintive quality of business graduates of Universiti Kebangsaan Malaysia.

The objective of this study is to explore the effectiveness of business simulation in teaching strategic management in terms of developing competent business managers. To complement the use of business simulation, this study also tries to identify the processes involved to support simulation game as a course project in order to achieve the objective of the teaching approach. By identifying the perceptions of the students on their experiences and problems in playing the game, future application of simulation game in teaching can be enhanced in achieving the objective of the course.

Business simulation has been used extensively in business education since it was first known use in university class fourty years ago. According to Wolfe (1993), this method has been extensively used in US and may have reached the point of relative saturation in American business courses. A study by Faria (1998), found that $97.5 \%$ of 236 randomly selected business schools in US used business simulation game. In UK, Burgess (1991) reported that $92 \%$ of business and management departments in polytechnics and $48.9 \%$ of UK universities were using business simulation games. However, the application of this teaching method in higher education in Asia is still limited (Du-Babcock \& Babcock, 2002; Chang, Lee, Ng \& Moon, 2003). The scenario is changing for the past 20 years; substantial accelerated growth is expected in this region. The drive to incorporate simulation in business education shifts the educational approach to not only focus on the cognitive elements, but also incorporates the affective and motivational aspects of learning through experiential learning that facilitates collaboration, peer learning, knowledge sharing and active learning.

According to Lean, Moizer, Towler and Abbey (2006), simulation approaches in learning are based on imitation of a system, entity, phenomenon, or process. Students are participating in a scenario, and they are expected to apply their knowledge to devise the best reaction to address the issues or problems posed in the simulation. Yorke (1981) has classified simulation into three types; role play, gaming and computer simulation. However, these three approaches of experiential learning are three separated activities; and therefore can be individually assessed in terms of effectiveness (Feinstein, Mann \& Corsun, 2002). Among these three, computer simulations present a more integrative system which aim to replicate system characteristics using mathematics or simple object representations (Feinstein et al., 2002) and gives a more realistic, complex, and yet flexible environment for players to participate in.

The interest in using simulation games in teaching business subjects is driven by its effectiveness. Relative to written case studies, Wolfe and Roge (1997) found higher learning effectiveness in simulation and this is supported by Kendall and Harrington (2003) that found similar results in hospitality courses. Herz and Mertz (1998) also report similar findings in economics subjects, and extended the effectiveness to all learning cycles. Business simulation is also reported to have positive association to individual learning and realism (Adobor \& Daneshfar, 2006). Moreover, the study exerts that individual learning still happens even when their performance in the competition is low.

The educational benefits of simulation can also be explained from cognitive perspective. By understanding how our mind works; stores, retrieves and utilizes information, instructional simulation researchers believe that this method is effective because of the full involvement in the learning process (Feinstein et. al, 2002). The activities in simulation games involve observation and reflection, creation of concepts, integration of observations into theories, and application of theories into decisions and problem-solving. Students learn through the sequential process of cause and effect, and learning by doing. This sequential process may also motivates the students to explore, experiment and learn independently, and the game-like atmosphere drives students' interest to be immersed in the game.

From affective perspective, simulation game helps in developing technical, professional and managerial skills (Trim, 2004). Through simulation, learning happens at two levels; individual and group. The development of intellectual capabilites is achieved through integration of various functional areas and the platform of dynamic 
environment reinforces learning integration. Group level learning is achieved through team dynamics that makes learning independent and helps develop interpersonal skills. Clarke (2009) summarizes the benefits/outcomes of simulation games in Table 1.

Table 1. Benefits/outcomes of simulation games

\begin{tabular}{lll}
\hline Elements & Benefits & Outcome \\
\hline Motivation & $\bullet \begin{array}{ll}\text { Students enjoy learning with higher } \\
\text { engagement in the subject because of } \\
\text { the close to real experience that is }\end{array}$ & $\bullet$ Deeper learning \\
difficult to replicate using traditional & $\bullet$ Increase motivation to learn \\
& $\begin{array}{l}\text { Increase ability to explore, experiment } \\
\text { and collaborate }\end{array}$
\end{tabular}
methods of teaching.

- Increase students' motivation, and by testing hypotheses and investigation of "what if" scenarios

Problem solving analytical thinking skills

Transfer of knowledge

Decision making and cross functional skill

Increased retention of knowledge

Adaptable learning

Behavioral, attitudinal and knowledge change
- The design of the simulation games that is based on actual business scenarios enhances students' understanding and ability to integrate management concepts and various functions of a business, in line with corporate strategies, business model and initiatives.

- Simulation allows knowledge transfer of theoretical and conceptual understanding to real business situations. Simulation becomes a training ground to practice business skills in risk-free learning environment.

- Learn and improve understanding of business functional areas, learn and improve their strategic management capacity, improve their teamwork capacity and leadership skills, and improve the "quality" of the corporate decisions they make.

- Students experience active learning through exploring, analyzing, communicating, creating, reflecting, or using new information or experiences in the instructional process.

- Students experience accelerated learning through dealing with complex situations that requires alignment between decisions and the dynamic environment.

- Provide coaching and remediation that increase ability to be able to adapt to different needs.

- Expected positive changes in students' attitude due to the changes in perspectives and mental models.
- Develop skills to apply intuition in decision-making especially in dynamic and complex environment.

- Active involvement of students in "almost real" decision-making situation.

- Increase ability to articulate knowledge which involves analysis from multiple perspectives in different situations.

- Deep understanding of theory and concepts based on application of knowledge in almost real situations.

- Self-learning from mistakes and repitition of application of new and modified knowledge to decision-making.

- Increase ability of students to apply theories and concepts learned through traditional methods.

- Build-up teamwork, leadership and social skills.

- Greater retention from active learning process.

- Development of problem solving skills

- Increase interest in the subject matter.

- Increase ability to adapt from mistakes and experiences.

- Able to align action with changes in the environment

- Become more proactive and dare to take risk.

- Self-learning through sharing of experiences and observations of one's action.

Adopted from: Clarke, E. (2009). Learning outcomes from business simulation exercises: Challenges for the implementation of learning technologies, Education and Training, 51(5), 448 - 459 
Although fourty years of research on the use of simulation in business education have shown the overwhelming potential of this method, it is still limited in use in some regions. Liu, Ho and Tan (2009) study on simulation game users and non-users in Taiwan and Australia suggest that major reasons for not using this approach in teaching are preparation time, funding, poor fit with course, and required changes in curriculum. This is extended by a study by Moizer and Lean (2010) on the diffusion model for simulation in business education that suggest persistent non-use is the result of insuitability of the simulation, inavailability of resources, and risk in implementation. However, the reasons were reported mostly by non-users. These study also suggested that increasing the awareness on simulation through engagement and creating the right conditions and support will increase the readiness and motivation of faculty members to apply this approach in teaching (Moizer \& Lean, 2010). This will lead to improvement in the cognitive and affective quality of business graduates and become a distinctive feature in the university's business program.

\section{Method}

Qualitative and quantitative designs were used to understand the effectiveness of business simulation. Students of strategic management (48 students) were assigned business simulation as course project and this project carried thirty marks (30). Students were divided into ten (10) groups consisted of 4 to 5 students in each group. These students were required to answer a set of questionnaire at the end of the course. The purpose of the questionnaire was to evaluate the perceptions of the students towards simulation games and its impact before and after the game. Besides answering questionnaire, interviews were conducted with each group during and at the end of the session.

\subsection{Sampling}

The sample for this study is Strategic Management students in Faculty of Economics and Management, University Kebangsaan Malaysia (UKM) in Semester 2, 2011/2012 session. The simulation game is Business Strategy Game: A Global Industry Simulation, an online game (http://www.bsg-online.com) created by Arthur A. Thompson and Gregory J. Stappenback. This game has been used previously as a supplement to Strategic Management text published by McGraw Hill. Recently, it became "a stand alone" software that need to be purchased separately. This simulation is also being used in business simulation competition at national level in Malaysia.

\subsection{Measurements}

Students were required to answer a set of questionnaire at the end of the game. The measurements were adapted from the works of Adobor and Daneshfar (2006) and Chang, Lee, Ng and Moon (2003). The questionnaire is divided into 5 sections. Section A consists of statements to understand educational benefits of simulation game, Section B is to assess the feelings in participating in this simulation game based on 4 dimensions; usefulness, clarity, attractiveness and challenge. Section $\mathrm{C}$ is to evaluate the impact of simulation game and Section $\mathrm{D}$ is to assess the teaching approach needed to support application of simulation game. Measurements in all sections were based on 5 point likert scale from strongly disagree/ highly ineffective to strongly agree/ highly effective. The frequency analysis of this study is based on the percentage of the agreed statements (4=agree/effective; $5=$ strongly agree/highly effective).

\subsection{Background of the Simulation Game}

In this business strategy game, group of students played the role of top management of an athletic footwear company that produces and markets both branded and private-label footwear. The students compete head-to-head against footwear companies run by other members of the class. As managers, students are responsible for assessing market conditions, determining how to respond to the actions of competitors, forging a long-term direction and strategy for their company, forecasting upcoming sales volumes, and making decisions relating to (1) production operations, (2) upgrading plants and expanding/reducing plant capacity (3) worker compensation and training (4) shipping and inventory management (5) pricing and marketing (6) bids to sign celebrities to endorse their brand of footwear (7) corporate social responsibility and citizenship and (8) financing of company operations.

The objective of each company is to enhance company's performance and build competitive advantage via strategic options such as low-cost leadership, differentiation, best-cost provider, focused low-cost, and focused differentiation. Each company's performance is based on a balanced scorecard that includes brand image, earnings per share, return on equity investment, stock price appreciation, and credit rating.

Group submitted their decision entry every week for eight weeks; submission of decision entry was on Thursday and result will be available on Friday. New cycle started every Friday. Student groups need to make two 
presentations; five-year plan and final presentation. The plan for the simulation game is illustrated in Figure 1 as below.

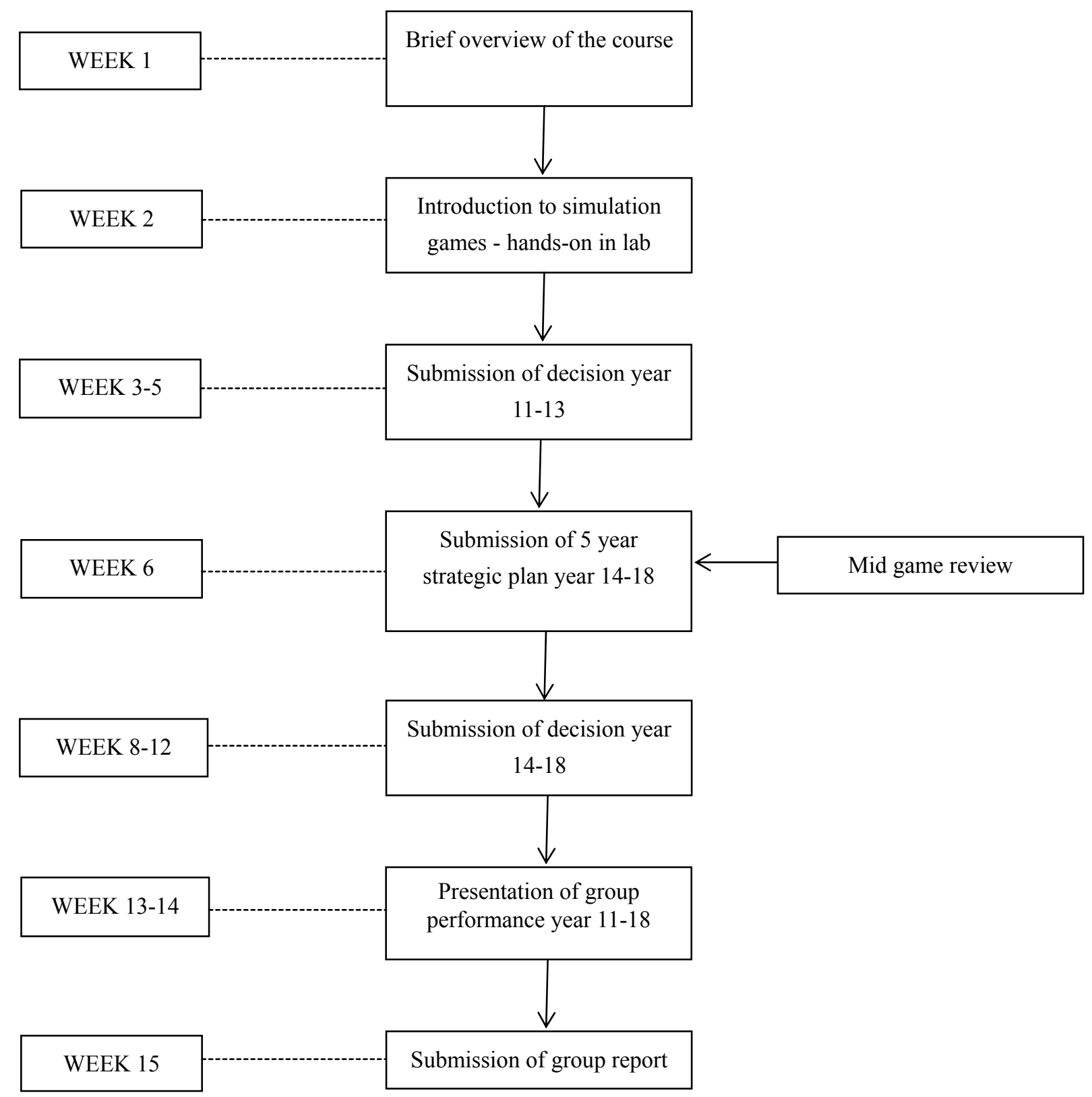

Figure 1. Flow chart for simulation game in strategic management course

\section{Results}

\subsection{Respondent Background}

Most of the students in this set were female (81\%) and most of them were above 20 years old. About $80 \%$ of the respondents were Malays and $20 \%$ were Chinese with $65 \%$ from the business administration program with various subject majorings. $50 \%$ of the students were from matriculation program. In terms of academic standing, about $67 \%$ of students scored more than 3.0 in their CGPA. 
Demography of the sample is presented in Table 2:

Table 2. Background of respondents

\begin{tabular}{|c|c|c|c|c|c|}
\hline Item & Freq & $\%$ & Item & Freq & $\%$ \\
\hline Gender & & & Age & & \\
\hline$\overline{\text { Female }}$ & 39 & 81.2 & Below 20 years & 1 & 2.1 \\
\hline Male & 9 & 1.8 & $20-25$ years & 47 & 97.9 \\
\hline Ethnicity & & & Nationality & & \\
\hline Malay & 38 & 79.2 & Malaysian & 48 & 100.0 \\
\hline Chinese & 10 & 20.8 & & & \\
\hline$\underline{\text { Program }}$ & & & $\underline{\text { Degree }}$ & & \\
\hline \multirow[t]{2}{*}{$\overline{\text { Internal }}$} & 48 & 100.0 & Business Administration & 31 & 64.6 \\
\hline & & & Accounting & 17 & 35.4 \\
\hline Majoring & & & Education & & \\
\hline Management & 7 & 14.6 & $\overline{\text { STPM }}$ & 13 & 27.1 \\
\hline Finance & 6 & 12.5 & Matriculation & 24 & 50.0 \\
\hline Marketing & 7 & 14.6 & Diploma & 10 & 20.8 \\
\hline Human Resources & 8 & 16.7 & & & \\
\hline International Business & 2 & 4.2 & & & \\
\hline Accounting & 17 & 35.4 & & & \\
\hline CGPA & & & $\underline{\text { Student year }}$ & & \\
\hline $2.00-2.49$ & 2 & 4.2 & Second year & & \\
\hline $2.50-2.99$ & 14 & 29.1 & Third year & & \\
\hline $3.00-3.49$ & 32 & 66.7 & Fourth year & & \\
\hline
\end{tabular}

\subsection{Educational Benefits}

Majority of the students gave positive feedback on the benefits of the simulation game. The highest score is evident in acquiring new knowledge (98\%) and integrate learning from functional areas (94\%). Besides these two, students also claimed that the game managed to increase their ability in business planning (92\%) and confidence to work $(92 \%)$. Other benefits with more than $90 \%$ score is enhancing real world knowledge and skills $(92 \%)$. The lowest score goes to aware own feelings and belief $(71 \%)$ and increase ability to write technical report (75\%). Based on Figure 2, it is evident that students felt simulation game beneficial where more than $80 \%$ of the students agreed with 23 statements of benefits. 


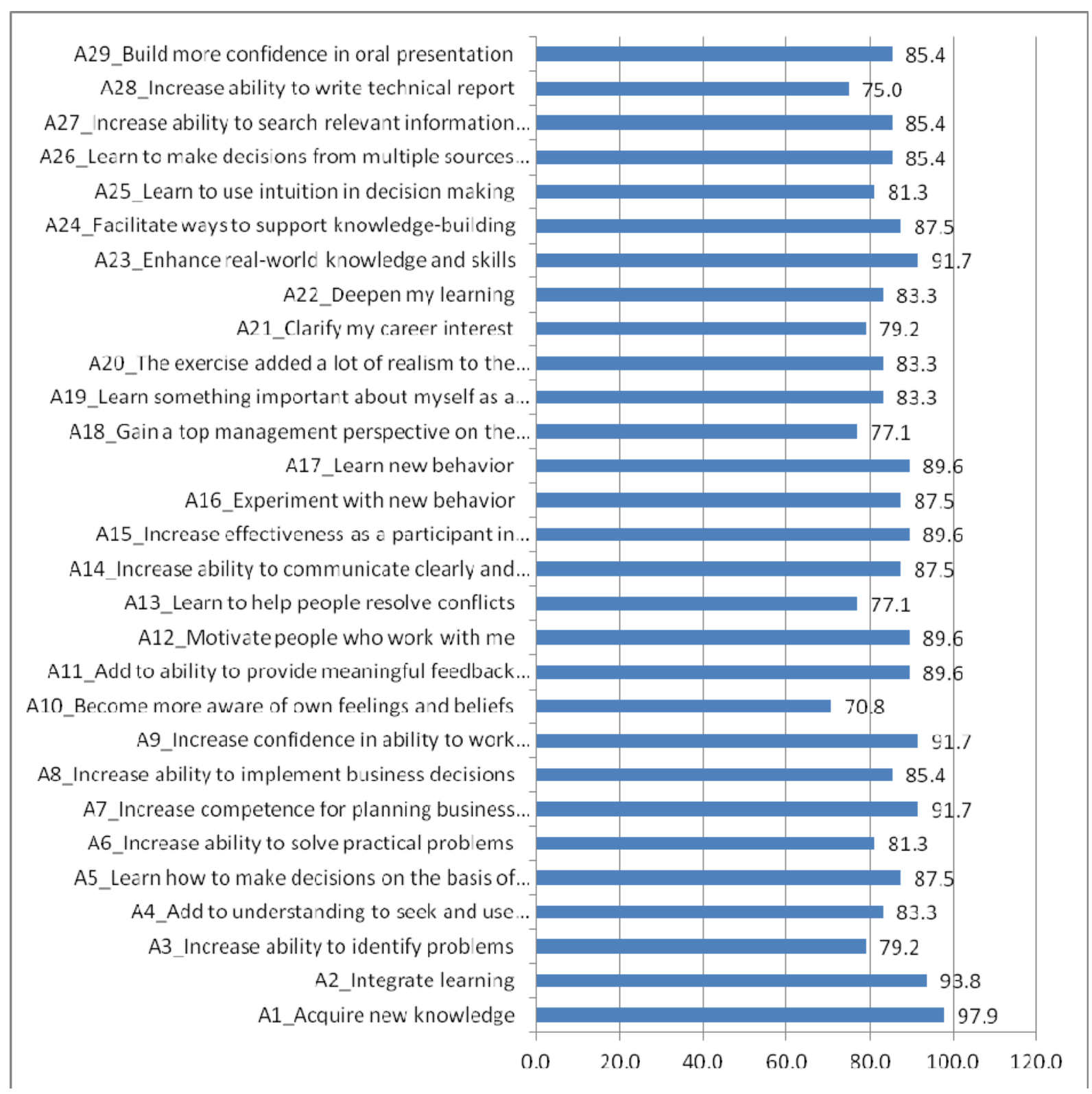

Figure 2. Benefits of the simulation game

\subsection{Experience and Feelings}

In section B of the questionnaire, students were asked to indicate their feelings about the game. As illustrated in Figure 3, more than $90 \%$ of the students agreed that simulation game able to transfer theory to practice and the game was challenging. More than $80 \%$ suggested that the game was interesting, creative, relevant and useful, and they learned important concepts from the game. The students also felt that the game was meaningful (79\%), lively (77\%), extraordinary (75\%), well organized (73\%), important (73\%) and exciting (73\%). On the other side, only $31 \%$ found the game as straightforward, and this conforms to only $38 \%$ of the students that found the game as easy to comprehend and $41 \%$ that found the game is clear. This is inline with almost $70 \%$ that claimed the game is difficult. This analysis has shown that although the students realized the benefits of the game and enjoyed playing it, they found the game difficult, not straightforward, not clear and time consuming, and these factors are the limitations of simulation applied in the course. 


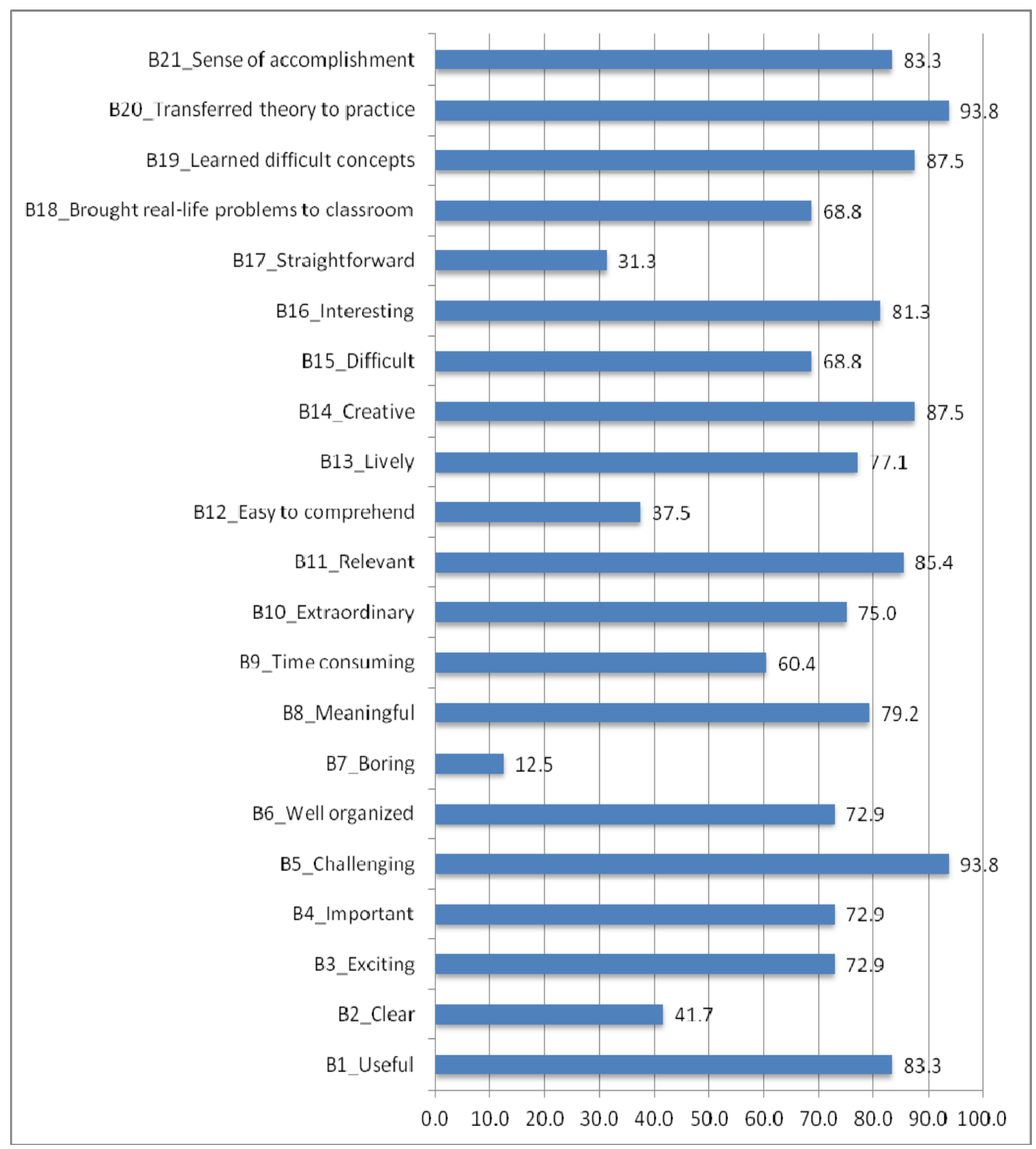

Figure 3. Student's feeling and perception about the game

\subsection{Impact of the Simulation Game}

To understand the impact of the simulation game to students in understanding the course content, students were asked in Section $\mathrm{C}$ to indicate their level of understanding before and after the game. Paired t-test were used to detect significant differences in the mean of each statements. The result shown below in Table 3 indicates significant positive differences in all items. 
Table 3. Impact of Simulation Game in Course Content

\begin{tabular}{lccc}
\hline \multicolumn{1}{c}{ Item } & t & df & Sig \\
\hline C1_Application of theoretical knowledge & 4.654 & 47 & .000 \\
C2_Environmental scanning & 5.770 & 47 & .000 \\
C3_Problem identification & 4.924 & 47 & .000 \\
C4_Problem solving & 4.654 & 47 & .000 \\
C5_Decision making & 4.648 & 47 & .000 \\
C6_Integration of functional knowledge & 4.654 & 47 & .000 \\
C7_Devising strategies & 4.242 & 47 & .000 \\
C8_Implementation of strategies & 3.289 & 47 & .002 \\
C9_Evaluation of strategies & 4.325 & 47 & .000 \\
C10_Business acumen & 4.497 & 47 & .000 \\
C11_Negotiation & 4.570 & 47 & .000 \\
C12_Team-working & 4.137 & 47 & .000 \\
C13_Leadership & 4.491 & 47 & .000 \\
C14_Self-discipline & 4.703 & 47 & .000 \\
C15_Communication & 5.011 & 47 & .000 \\
C16_Confidence & 4.718 & 47 & .000 \\
C17_Self-scheduling & 4.594 & 47 & .000 \\
C18_Motivation & 4.779 & 47 & .000 \\
\hline
\end{tabular}

\subsection{Teaching Approach}

The objective of section D of the questionnaire is to gauge the teaching approach that supports the application of simulation game. As illustrated in Figure 4, more than $80 \%$ agreed that students should be given the liberty to form their own team, and everyone should participate in the presentation. Students also suggested that more time should be given to them to read the manual $(73 \%)$ and instructor should monitor and give feedback from time to time (73\%). However, more than $60 \%$ wanted the freedom to play the game on their own. From the responses, it highlights possible reasons to why students find this game difficult; the students seem to have problem reading and understanding the manual. More than $60 \%$ claimed that they need more time to read the manual, therefore they agreed that it should be given in the first week of the semester ( 2 weeks to read the manual), difficult to understand the terms in the manual, not enough information in the manual, and example or practice should be illustrated at the beginning of the course. On the other side, they agreed that marks allocation and time for presentation are adequate, the game is assigned as group work, report is written in English, presentation is essential, and the time length of the game ( 8 cycles) is sufficient. The students also acknowledged the game as interesting, fairly user-friendly and exposed them to real business experiences. 


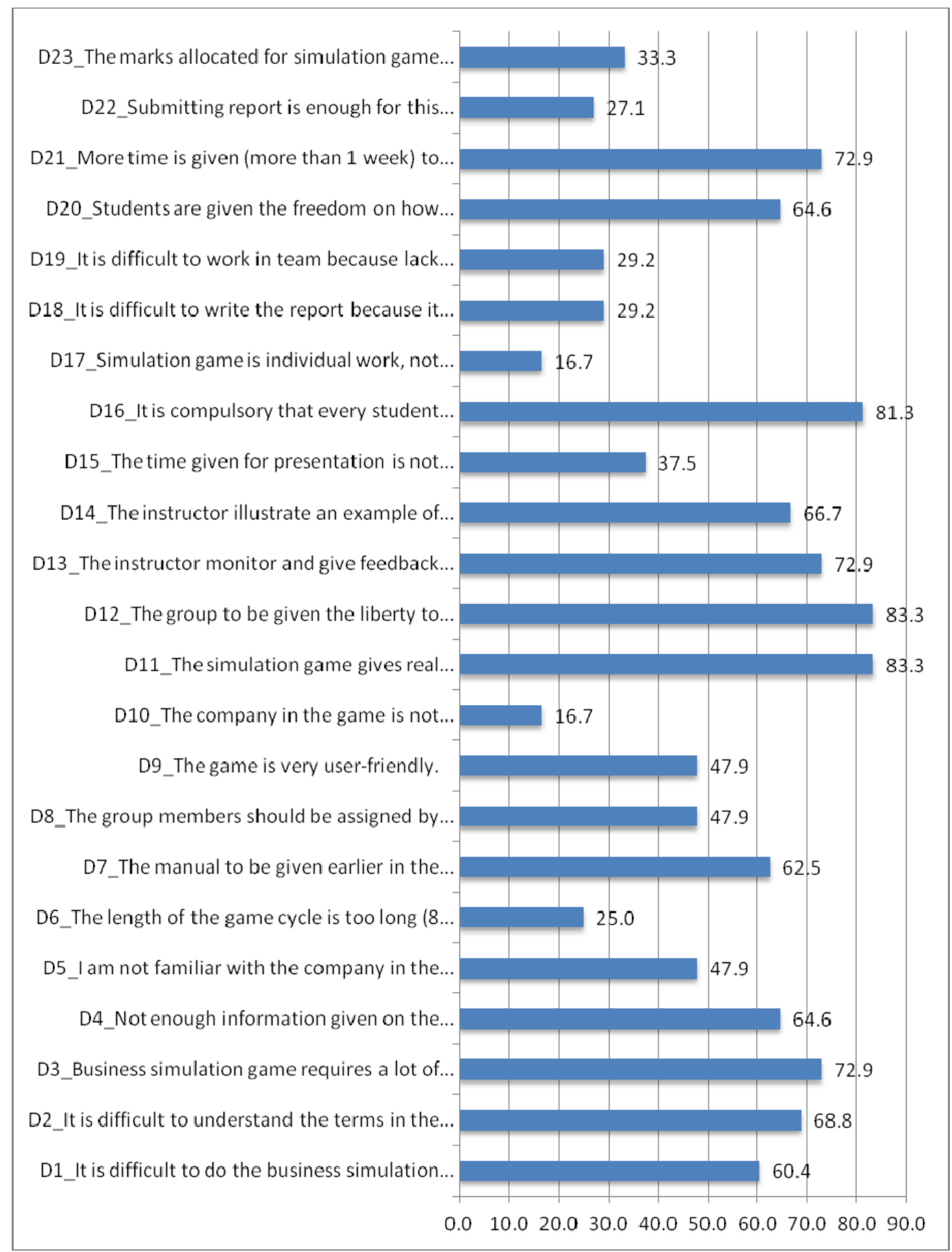

Figure 4. Perceptions on simulation game approach in teaching

\section{Discussion}

One of the promising outcomes of simulation game is its ability to teach students to apply multi disciplinary decision making (Chakravorty \& Franza, 2005). In the analysis of simulation in relation to hospitality industry, students benefit mosts in financial analysis and marketing in relation to strategic management process and strategic decision making (Kendal \& Harrington, 2003). This study also indicates that students appreciate the multidisciplinary qualities of business simulation. The dynamic nature of the game deepens learning because the students are required to incorporate changes in external and internal variable in the decision-making. Although this feature complicates the game to students, they appreciate the realism it presents. Another significant benefit of simulation is students learned the concept of intuition. This is gathered from the interview where students explained how they applied intuition in making strategic decisions involved in the game. In strategic management, decision making involves not only factual information, but it also involves the application of 
intuition (David, 2013). Many teachers of strategic management struggles to explain the application of this concept in strategy making, and yet simulation able to translate this concept to practice.

In terms of students' feelings toward the game, a study in United States and Australia also yield similar results; business strategy game made the course more interesting and learning more realistic because the game allowed them to apply what they have learned in real-life situation (McKenna, 1991; Stone, 1995). Other studies also found that the pressure of decision making in the game gave the students dynamic reality of the business environment. For example, Stone's study (1995) reported that more than $60 \%$ of the students could feel the pressure faced by strategy makers. In this study, the impact of decision making is reported from the interview conducted with student groups. They mentioned that they need to really understand the impact of their decision and felt nervous every time the result was released. Students looked forward to know their results and excited to implement their planned activities in the coming cycles.

The problem of language is also apparent in studies conducted in countries where English is the second language. The outcome of the survey is similar to findings of other research in different context. For example, a study on more than 200 students in Hong Kong (Chang et. al, 2003) suggests that simulation game is fun and interesting, but the students also faced problems in understanding and reading the manual. From the responses, more time is needed for the students to read the manual and a session of question and answer should be conducted to deliberate the manual with the students. In other words, more preparation time would give the students some advantages before the actual game. By reducing the obstacle in the game from the language aspects, it will give a better evaluation on the level of understanding of the subject as the result of playing the game.

This is supported by the suggestions from Adobor and Daneshfar (2006) that the ease of use has a positive effect on the performance of the team. It signifies that the physical architecture of the game will affect how much the students can learn and this implies the importance of user friendly features in the application. By reducing computer model complexity, assessment of learning from game variable complexity will be more valid. Besides this, student engagement will increase because they will be motivated and excited in the process of decision making, and it will also avoid frustration from technical exhaustion. Therefore, the findings illustrated the importance of ease of use in both language and technical aspects of the game.

The simulation exercise also managed to increase team dynamics. Studies have shown that interpersonal, communication and teamwork improves through simulation (Noy, Raban, \& Ravid, 2006; Dasgupta \& Garson, 1999, Faria, Hutchinson, Wellington \& Gold, 2009). Internet technology plays an important role in helping students to communicate and participate effectively, and the greater traffic of communication of ideas increases the learning from simulation.

One unique feature of simulation is that students learn from understanding the impact of their decision. This is absent in case study approach which only allows students to make rational judgment and suggestions, without knowing the effect of their decisions if they were implemented. Although the environment in simulation is fictional, the students receive feedback from the consequences of their decisions, and allow them to reevaluate the environment to reformulate strategies. Students learn from repeated iterations of the decision making process, and this experience is valuable in their future career.

\section{Implication to Business Education}

Incorporating simulation involves resources; financial, time, and effort, and the impact to the students can be negative without careful considerations. Since most simulation applications are developed based on Western environment, careful selection of the game is important to ensure its effectiveness in learning. Basically, realism and user-friendliness are the most important features to be considered. Adobor and Daneshfar (2006) propose three main features to assess simulation game; team dynamic, user-friendliness and realism, and King and Newman (2009) suggest the evaluation to be based on user and technical perspectives. The absence of simulation game based on Asian business environment made it more compelling for instructional simulation researchers to develop suitable business simulation for universities in the Asian region.

It is also important for instructors to emphasize on the goal of the game. Students are easily frustrated if they are not performing well in the competition, and this may reduce the potential of learning. Therefore, the assessment of student's performance must be multi-faceted; team dynamics, communication, commitment, and students must be clearly informed of the objectives of the game. Reflection may also be a good tool to support simulation and can simultaneously be an effective measurement tool for student's performance. Besides that, online forum can be used as an avenue for students to ask questions and discuss issues in simulation. Sharing of ideas among students may also deepen the process of learning. 
Since most application of simulation in classroom tend to use teams to represent firms that compete against each other in an industry, students must be clear on the link between task conflict and learning. Instructors need to emphasize the positive benefits of healthy and vigorous debates of issues before making their decisions. They should be reminded that personal conflict should be avoided due to its dysfunctional effects on the team. The existence of personal conflict in the team will jeopardize the team capabilities and motivation to focus on the game, and make learning objective unachievable.

Using simulation game in business education brings many benefits beyond traditional forms of instruction. This mode of experiential learning is able to achieve the objective of education not only from the cognitive perspective, but the built-in motivational mechanism in the design of the game deepen students' learning. Business simulation game allows students to visualize situations and see the impact of decisions made in a dynamic environment. By immersing students through full involvement in the game, students gain almost real experiences of decison-making processes that involve team and conflict management, leadership and negotiation. The potential growth in business simulations in the Asian region is enormous, and this is evident from the excitement and engagement of students participating in the game as shown in studies within this region. As suggested by Kendall and Harrington (2003), simulation should not be considered as an alternative; instead, simulation is definitely an additional or supplemental pedagogy that will effectively increase the learning curve. The use of business simulation game will definitely refresh business education and bring new breed of business graduates to the market.

\section{References}

Adobor, H., \& Daneshfar, A. (2006). Management simulations: Determining their effectiveness. Journal of Management Development, 25(2), 1151-168. http://dx.doi.org/10.1108/02621710610645135

Aranda, D. A. (2007). Simulating reality for teaching strategic management. Innovations in Education and Teaching International, 44(3), 273-386.

Behrman, J. N., \& Levin, R. I. (1984). Are business school doing their job. Harvard Business Review, 62(1), 140-147.

Burgess, T. F. (1991). The use of computerized management and business simulation in United Kingdom. Simulation \& Gaming, 22(2), 174-195.

Chakravorty, S. S., \& Franza, R. M. (2005). Enhancing cross-functional decision making: A simulation approach. Decision Science Journal of Innovative Education, 3(2), 331-337.

Chang, J., Lee, M., Ng, K., \& Moon, K. (2003). Business simulation games: The Hong Kong Experience. Simulation Gaming, 34(3), 367-376. http://dx.doi.org/ 10.1177/1046878103255877

Chonko, L. B., \& Caballero, M. J. (1991). Marketing madness, or how marketing departments think they're in two places at once when they're not anywhere at all. Journal of Marketing Education, 13(1), 14-25.

Clarke, E. (2009). Learning outcomes from business simulation exercises: Challenges for the implementation of learning technologies. Education and Training, 51(5), 448-459. http://dx.doi.org/10.1108/00400910910987246

Curry, B., \& Moutinho, L. (1992). Using computer simulations in management education. Management and Education Development, 23, 155-167.

Dasgupta, S., \& Garson, G. D. (1999). Internet simulation/gaming. Simulation \& Gaming, 30, $20-22$.

David, F. R. (2013). Strategic Management: Concept and Cases (14th ed.). England: Pearson.

Du-Babcock, B., \& Babcock, R. D. (2002). Adapting an American-based simulation to a Hong Kong classroom. Business Communication Quarterly, 63(2), 9-40. http://dx.doi.org/ 10.1177/108056990006300202

Faria, A. J. (1998). Business simulation games: Current usage levels - an update. Simulation and Gaming: An International Journal, 29(3), 295-309. http://dx.doi.org/ 10.1177/1046878198293002

Faria, A. J., Hutchinson, D., Wellington, W. J., \& Gold, S. (2009). Developments in business gaming: A review of the past 40 years. Simulation Gaming, 40(4), 464-487. http://dx.doi.org/10.1177/1046878108327585

Feinstein, A. H., Mann, S., \& Corsun, D. L. (2002). Charting the experiential territory: Clarifying definitions and uses of computer simulation, games, and role play. Journal of Management Development, 21(10), $732-744$. http://dx.doi.org/10.1108/02621710210448011 
Herz, B., \& Mertz, W. (1998). Experiential learning and the effectiveness of economic simulation games. Simulation Gaming, 29(2), 238-250. http://dx.doi.org/10.1177/1046878198292007

Hughes, T., O'Regan, N., \& Wornham, D. (2008). The credibility issue: Closing the academic/practitioner gap. Strategic Change, 17(7), 215-233.

Kendal, K. W., \& Harrington, R. J. (2003). Strategic management education incorporating written or simulation cases: An empirical test. Journal of Hospitality \& Tourism Research, 27(2), 143-165. http://dx.doi.org/10.1177/1096348003027002001

King, M., \& Newman, R. (2009). Evaluating business simulation software: Approach, tools and pedagogy. On the Horizon, 17(4), 368-377. http://dx.doi.org/10.1108/10748120910998399

Lean, J., Moizer, J, Towler, M., \& Abbey, C. (2006). Simulations and games: Use and barriers in higher education, Active Learning in Higher Education, 7(3), 227-242. http://dx.doi.org/10.1177/1469787406069056

Liu, C. H. A., Ho, C. T., \& Tan, K. H. (2009). The application of management simulation and game teaching in Taiwan and Australia. On the Horizon, 17(4), 397-407. http://dx.doi.org/10.1108/10748120910998326

MacKay, R. B., \& McKiernan, P. (2004). Exploring strategy context with foresight. European Management Review, 1(1), 69-77.

Martin, D., \& McEvoy, B. (2003). Business simulations: A balanced approach towards tourism education. International Journal of Contemporary Hospitality Management, 15(6), 336-339.

McKenna, R. J. (1991). Business computerized simulations: The Australian experience. Simulation \& Gaming, 22(1), 36-62.

Mitchell, R. C. (2004). Combining cases and computer simulations in strategic management courses. The Journal of Education for Business, 79(4), 198-204.

Moizer, J., \& Lean, J. (2010). Toward endemic deployment of educational simulation games: A review of progress and future recommendations. Simulation Gaming, 41, 116-131. http://dx.doi.org/10.1177/1046878109359052

Noy, A., Raban, D. R., \& Ravid, G. (2006). Testing social theories in computer-mediated communication through gaming and simulation. Simulation \& Gaming, 37, 174-194.

Snyder, L. G., \& Snyder, M. J. (2008). Teaching critical thinking and problem solving skills. The Delta Pi Epsilon Journal, 2, 90-99.

Stone, R. A. (1995). The business strategy game: Faculty experience and student perceptions. Journal of Management Education, 19(2), 281-289.

Trim, P. R. J. (2004). Human resource management development and strategic management enhanced by simulation exercises. Journal of Management Development, 23(4), 399-413.

Wolfe, J. (1993). A history of business teaching games in English-speaking and post-socialist countries: The origination and diffusion of a management education and development technology. Simulation \& Gaming, 24(4), 446-463.

Wolfe, J., \& Roge, J. N. (1997). Computerized general management games as strategic management learning environments. Simulation \& Gaming, 28(4), 423-441.

Yorke, D. M. (1981). Patterns of Teaching. London: Council for Educational Technology. 